\title{
De como ensinar o indefinível ${ }^{\mathrm{i}}$
}

Gonzalo Armijos Palacios ${ }^{\mathrm{ii}}$

\section{Resumo}

No presente artigo se discutem alguns problemas inerentes às definições de filosofia, particularmente analisa-se a versão popular de ser ela 'criação de conceitos'. Refletimos sobre os vários problemas que essa definição encerra e as situações paradoxais que provoca quando a pensamos no contexto do ensino da filosofia acadêmica brasileira.

Conceber o filosofar como criação de conceitos desvela a possibilidade de a filosofia não ser mais do que outro gênero literário.

O pensar filosófico é talvez a única atividade acadêmica que, ao voltar-se reflexivamente sobre si, não sai de si. Por que, quando o pensar filosófico quer se reconhecer mediante aquilo que se acostumou em chamar de giro metafilosófico, permanece no plano filosófico, diferentemente de outras atividades racionais? Quando o biólogo, o químico ou mesmo o historiador refletem sobre a natureza da biologia, da química ou da história, não fazem biologia, química ou história. De alguma forma se situam fora delas. Não assim o filósofo ao pensar sua própria atividade.

Encontramo-nos frente a um dilema. Em primeiro lugar, com que fundamento podemos afirmar que realizamos uma atividade indefinível? Mas, por outro lado, sobre que base afirmaríamos o oposto, isto é, que realizamos uma atividade claramente definível e definida? No último caso, como compatibilizar definições antagônicas, irreconciliáveis ou mesmo incomensuráveis entre si? Com que direito escolher uma entre tantas e tão diversas definições - algumas delas dadas pelos próprios clássicos da filosofia? Como ensinar filosofia, ou melhor, a filosofar, privilegiando-se uma entre tantas definições e concepções do que é filosofar - e, portanto, escolhendo-se uma entra tantas e tão dissímeis formas de se filosofar?

Se, por outro lado, a filosofia é mesmo indefinível, como ensinar uma atividade que já é entendida como tal? Como ensinar algo que, por constatações teóricas e históricas, foi feito e se faz, existiu e existe das mais variadas formas?

Numa ocasião comecei minhas aulas de Filosofia Antiga na turma do primeiro ano dizendo, entre outras coisas, que os estudos que eles estavam começando se centraria no 
pensamento filosófico ocidental. Uma jovem estudante me questionou sobre a razão de a matriz curricular deixar de fora a filosofia oriental. Frente a esse tipo de pergunta, um professor pode responder de várias formas. Uma delas é dizer que o que se conhece como filosofia oriental não é, de fato, filosofia. Não, pelo menos, do ponto de vista do que se considera como filosofia na cultura ocidental. Por melhor fundamentada - e bem intencionada - que tal resposta possa ser, resulta no mínimo curioso que se use o substantivo 'filosofia' para o que, pelo que se afirma, não seria filosofia. Pois se chama de filósofos pensadores que não possuem, nem de forma aproximada, uma concepção de filosofia que a define de forma a excluir tudo o que estes filósofos fazem ou fizeram. É bom notar que negar o caráter filosófico a tudo o que não se assemelhe ao que se faz no Ocidente parte de uma posição que, no final, vai resgatar apenas uma forma de se fazer e conceber a filosofia dentro da própria cultura ocidental. Minha resposta foi dizer que a razão de nossa grade curricular ter deixado de fora o pensamento oriental se devia, fundamentalmente, ao fato de nenhum dos professores do curso ter formação ou conhecimento nessa área do pensamento humano, que nenhum de nós tinha estudado, vivido ou se preocupado pelo que se faz nessas diversas partes do mundo que chamamos de Oriente. De qualquer forma, deixei claro que não havia nenhuma concepção oficial do curso sobre o caráter não-filosófico do pensamento oriental, o que era verdade. Minha resposta foi, de fato, uma constatação e penso que nenhum curso deva ter uma deliberação sobre se na sua grade curricular iriam ou não constar disciplinas do que possa se considerar filosofia oriental. O assunto, penso francamente, é simples e olimpicamente ignorado.

Continuamente me surpreendo pensando sobre isso e vejo que, efetivamente, nosso distanciamento do pensamento oriental se explica, entre outras coisas, pela nossa ignorância quase total e geral, unida a nossa falta quase absoluta de interesse respeito do que se faz, culturalmente falando, em outras partes do planeta que não sejam Europa e os Estados Unidos.

Agora, olhando concretamente no que se fez naquilo que se chama de filosofia ocidental - ou, de outra forma, do que os ocidentais chamamos 'filosofia' - temos várias surpresas. Só esticando convenientemente o termo de 'sabedoria' podemos incluir os 'amantes do saber' dentro de uma e a mesma categoria. Porque, efetivamente, os interesses de Tales, Anaximandro e Anaxímenes são completamente diferentes de outros também chamados 'filósofos', mas que possuem um tipo de 'saber' e, portanto, outro tipo de 'amor pela sabedoria', como Heráclito e Parmênides. Cuja sabedoria, ou amor pelo saber, nada 
parece ter em comum com o tipo de saber e amor pelo saber de um Anaxágoras, um Empédocles, de um Leucipo ou, mais ainda, de um Epicuro.

O problema que para uma definição única, uniforme e abrangente de filosofia todas essas diferenças trazem pode ser visto se chamarmos, cada uma das visões desses pensadores, de 'cosmovisões', 'visões do mundo e da vida' ou 'paradigmas'. O fato é que ao longo da história do pensamento filosófico ocidental podemos ver as concepções e definições mais díspares de 'filosofia’ e 'filosófico’. O que para um clássico da filosofia é filosófico não é nem poderia sê-lo para outro. Mesmo assim, tanto um quanto outro são considerados pela história ocidental da filosofia filósofos. O que não ocorre, por exemplo, com os alquimistas e os químicos. O que os alquimistas faziam não é química, nem alquimia, o que os químicos fazem. Mas o que os pré-socráticos faziam era considerado filosófico e ainda pode ser considerado filosófico. De qualquer forma, num momento do tempo foi filosófico, mesmo que depois tenha deixado de sê-lo - o que por si já é um assunto filosoficamente interessante.

O fato é que houve e há, então, formas de se fazer filosofia. E é importante notar que uso dois tempos verbais, o que põe o ato de filosofar numa dependência temporal. Isso vemos também em Aristóteles que na Metafísica se refere a alguns pré-socráticos como filósofos físicos. Assim, se há filósofos físicos haverá filósofos não-físicos o que mostra que há modos diversos de se pensar e aos que podemos chamar de filosóficos, mesmo que tenham concepções díspares sobre sua atividade intelectual.

A questão é que essas formas diversas de se fazer filosofia, ou a possibilidade de haver filósofos que fazem coisas diferentes e que concebem diferentemente sua própria atividade, impedem, se não impossibilitam, a construção de uma definição de filosofia como aquelas a que estamos acostumados. Por exemplo, uma por gênero próximo e diferença específica. Algo assim como “a ciência da verdade”, ou “o pensamento das essências”. Fazendo isso, penso, sempre deixaríamos algum filósofo de fora. Pelos exemplos, todos os céticos ou os filósofos não essencialistas. Noutras palavras, toda definição positiva de filosofia, “filosofia é x”, “filosofia é y”, deixa de fora, negativamente, formas que a própria cultura acadêmica considera como filosóficas, o que não deixa de ser curioso, se não paradoxal. O simples fato de pensadores que vão dos pré-socráticos aos contemporâneos serem considerados filósofos prova isso e ao mesmo tempo representa um obstáculo formidável para quem pretende definir, numa só fórmula, tudo aquilo que esses pensadores e pensadoras fizeram ou fazem.

II

Nas artes, nas letras, na filosofia, definir equivale a empobrecer uma riqueza potencialmente infinita. 
Se o que se denomina 'filosofia' fosse algo definível, como é definível, digamos, 'triângulo', de alguma forma já estaria antecipado, desde o início da filosofia, o que o resto de filósofos faria. Ou melhor, se a geometria tivesse sido definida como criação de figuras geométricas, todo geômetra deveria criar sua forma geométrica própria, o que confirmaria que ela, de fato, consiste na criação de novas figuras geométricas. Assim como não podemos delimitar, empobrecer isto é, a geometria por meio de uma definição que privilegia um fazer geométrico específico, como poderíamos definir a filosofia afirmando que ela é, e só pode ser, uma e apenas uma determinada atividade? A verdade é que a história do que se conhece como filosofia não apresenta uma unidade em nenhum aspecto - isto é, no dos seus objetos, problemas, temas ou métodos. Isto é, não vemos um só método, mas métodos os mais diversos. Tampouco há um só tema, ou um ou dois problemas, e os objetos filosóficos se multiplicam à medida que o tempo passa. O que vemos é rupturas em cada um desses aspectos. Não podemos ignorar, portanto, que os que são reconhecidos como grandes clássicos da filosofia não imaginaram que ela pudesse ser concebida ou definida como o fizeram filósofos posteriores ou como aparece concebida, delimitada ou definida nas introduções ou manuais de filosofia. Os problemas que aparecem ao longo do tempo são tão diferentes como os pensadores - incluídos os pensadores e pensadoras da mesma época. A verdade é que os enfoques, objetos, problemas, temas e maneiras de filosofar não foram nem podem ser antecipados por épocas anteriores. O que vale para nós, pois não podemos sequer imaginar, hoje, quais serão os problemas filosóficos, ou os temas, sobre os que se debruçarão na segunda metade do século XXI. Dizer que é possível fazer isso é introduzir uma continuidade temático-problemática que não existe na filosofia e, portanto, falsificá-la e empobrecê-la.

Se, por outro lado, houvesse algum tipo de unidade temática, problemática, metodológica e objetual, haveria também continuidade nos problemas, objetos, temas ou métodos filosóficos. Se esse é o caso, como se explica, então, que não seja possível relacionar todos os filósofos, seja tematicamente, seja metodologicamente, ou pelos problemas ou enfoques que tiveram? A verdade é que não há continuidades, mas rupturas e, consequentemente, não há unidade. Há filósofos que não só não falam a mesma língua como não poderiam ter suas teses ou teorias traduzidas na linguagem, teses ou teorias de outros filósofos - precisamente por não compartilharem enfoques, problemas, temas, objetos nem métodos. Enquanto que para um filósofo a filosofia é o “galo das Gálias” que canta a aurora de um novo dia, para outro é a “coruja de Minerva”, que levanta seu vôo ao entardecer. Se formos fazer uma lista do que para cada grande filósofo, ou filósofa, é a filosofia, ou qual sua 
função, seu método, seu objeto etc., veríamos que dificilmente poderia ser extraído dela algo que possa ser comum ou mesmo compreensível. A filosofia é como as artes, definir as artes pelos padrões musicais, ou pictóricos ou por critérios escultóricos, é empobrecer o que de por si é rico, multiforme e de potencialidades infinitas.

III

É notável que não seja fácil prender o vôo filosófico numa única definição de 'voar' nem de 'voar filosoficamente’.

A concepção (ou definição) de filosofia como criação de conceitos pode servir para mostrar claramente a impossibilidade de reduzir tudo o que de fato é considerado filosófico a uma e apenas uma concepção ou definição do que ela seja. (Antecipo que não estou tomando essa concepção como prescritiva, mas como descritiva - pois uma coisa é dizer “filosofia deve ser criação de conceitos” e outra, muito diferente, “filosofia é, sempre foi, e sempre será, criação de conceitos”.) Se quem afirma que a filosofia é criação de conceitos pretende com isso dizer que ela sempre foi, é e será isso, então, podemos constatar que quiçá nunca foi esse o objetivo claro e consciente dos filósofos clássicos e, com isso, chegar num ponto no mínimo curioso: os grandes filósofos nunca souberam de que se tratava o que estavam fazendo! Quando escuto uma definição de filosofia, imediatamente penso em alguém que seja considerado realmente um filósofo ou filósofa e me pergunto duas coisas: se há nele algo que (1) confirme ou (2) antecipe essa concepção de filosofia. Isto é, se a obra ou o trabalho dessa filósofa ou filósofo confirmam essa definição e, em segundo lugar, se há algum filósofo clássico que tivesse antecipado que a filosofia é criação de conceitos ou que possamos ver que seu interesse era, digamos, não resolver problemas, mas criar conceitos. Sem dúvida, podemos achar exemplos importantes de conceitos criados e fornecidos por muitos filósofos. A questão não é se há ou não criação de conceitos na filosofia, como há na matemática ou em outra ciência, o problema é se exclusivamente para criar conceitos que os filósofos têm em mente quando começam a pensar filosoficamente!

Penso que a filosofia é essencialmente criativa, imaginativa e chega a ser fantástica, como a literatura. Mas a criação filosófica, como a literária ou a matemática ou a física, não se reduz a ser deste ou daquele conceito. Criam-se, ou apresentam-se, visões do mundo, da estrutura do universo, da vida, do político, do belo e de quantas coisas interesse individualmente a cada cientista, a cada literato, a cada filósofo. Em que se diferenciaria a filosofia, como criação de conceitos, da matemática, física, biologia ou qualquer outra ciência em que também há criação de conceitos? Dizer que a biologia cria conceitos biológicos e a 
filosofia, filosóficos, não é explicar nada sobre a natureza nem de uma nem de outra. Há algo mais, então, que faz que a biologia seja biologia, a matemática, matemática e a filosofia, filosofia.

Surge, no entanto, um problema quando pensamos na criação de conceitos, não como uma simples definição de filosofia, mas como uma exigência, uma necessidade sine qua non do trabalho filosófico. Pois ele não poderia se originar da forma em que de fato se origina.

Pensemos agora no seguinte: se um texto devesse ser considerado filosófico fosse segundo o critério da criação de conceitos, então, o leitor desse texto deveria ter lido toda a história da filosofia, e conhecer todos os conceitos que nela existem, para poder decidir se o texto é de fato filosófico, o que é, por um lado, falso, por outro, esdrúxulo. Pois não precisamos conhecer toda a história da filosofia para dizer, ao lermos qualquer texto, se é ou não filosófico. É, então, outra coisa que nos leva a dizer: “sim, este é um texto filosófico”.

Se, além disso, a exigência do trabalho filosófico fosse a de criar conceitos, as pessoas iriam à filosofia com o peso de ter de criar algum ou mais conceitos filosóficos para que suas reflexões possam ser consideradas filosóficas. Isso imporia uma exigência difícil de se cumprir e impediria o fluir natural da reflexão filosófica quando esta ocorre. Quem é realmente capaz de provar que todos os grandes filósofos, antes de filosofar, pensaram: “agora vou criar um conceito filosófico”. No entanto, olhando o que os filósofos fizeram, não vejo que ninguém procedeu nas suas reflexões seguindo esse critério. A criação de conceitos pode ser uma consequência, mas certamente não é $a$ finalidade nem $o$ requisito do que se fez e se faz na filosofia.

Quando alguém pretende definir a filosofia em sentido forte - ou seja, quando se pretende com essa definição dizer o que ela necessariamente foi, é e será - devemos sempre olhar a realidade (o passado e o presente), e ver se a realidade confirma essa definição. $\mathrm{O}$ fato é que aquelas definições universalistas e essencialistas podem ser confirmadas apenas por uma ou duas grandes figuras filosóficas. Mas uma ou duas andorinhas, por mais clássicas que sejam, não fazem nem fizeram o verão filosófico.

IV

Se a criação de dogmas destrói e aprisiona a criatividade, sua destruição liberta e estimula infinitas criatividades.

Se pensarmos que o trabalho com os estudantes de filosofia consiste em levá-los a filosofar, dizer simplesmente que a filosofia é - única ou essencialmente - criação de conceitos pode criar algumas dificuldades. Pois, eventualmente, deveríamos avaliar o 
crescimento filosófico dos futuros filósofos pela criação, por parte deles, de um ou mais conceitos filosóficos.

Assim, se alguém afirmasse que formou filósofos, vai ter de apresentar, como prova disso, os conceitos criados por esses estudantes. E se o professor de filosofia se apresenta como filósofo, ele mesmo deveria dizer quais conceitos filosóficos criou. E isso se deveria aplicar, igualmente, para os trabalhos de conclusão de curso, seja de graduação ou pósgraduação. Se, no entanto, déssemos uma olhada nos títulos das dissertações de graduação, mestrado e doutorado do país veríamos, quase que invariavelmente, que os professores orientam trabalhos que na sua grande maioria são comentários de obras ou de conceitos de filósofos consagrados, não dos seus, estudantes, próprios conceitos. E daí resulta uma situação esquisita: que fazem então os cursos de filosofia, seja da graduação, seja da pós-graduação no Brasil? Preparam seus estudantes para criar conceitos próprios? Consta isso como o objetivo precípuo de seus projetos pedagógicos? Parece que a resposta é óbvia. Não há no Brasil um curso que tenha esse como seu objetivo. Ora, se a filosofia é criação de conceitos, e nenhum curso de filosofia no Brasil prepara seus estudantes para criar conceitos, isto é, para filosofar, para que os prepara então?!

O fato é que fazer a pergunta "qual é o conceito ou conceitos filosóficos que você criou?” é defender uma concepção de filosofia problemática em vários sentidos. Em primeiro lugar, a concepção de filosofia que está por trás da pergunta parece não resgatar o que, de modo geral, mas nem por isso menos verdadeiro, podemos chamar de ato de filosofar. Desde o início dos mais variados atos de filosofar vemos a identificação de problemas, que é precisamente o que motiva a reflexão filosófica. Lembremos que, segundo Aristóteles, é o espanto que leva a filosofar. Por outro lado, na busca da solução parece não estar, em momento algum nem como objetivo central, a necessidade da criação de um conceito. Por exemplo, se meu problema é descobrir se há valores estéticos essenciais ou são estes meras convenções humanas, não vejo que na solução dessa questão deva, necessariamente, chegar a criar algum conceito. Pois é óbvio que nem toda solução de um problema termina com a criação de conceitos. Em alguns casos, aliás, a solução do problema é sua dissolução, ou a constatação de que era um pseudo-problema. (Quem leu alguma vez Wittgenstein, que é considerado um filósofo, pode constatar isso.)

Se num curso de música formamos compositores, é claro que os egressos desse curso deverão formar-se apresentando suas composições, pois é isso que os torna compositores. Como pintar torna os estudantes de pintura pintores, e atuar, aos de teatro, atores. A um 
arquiteto que não materializou um projeto não o chamaríamos de arquiteto, nem ao engenheiro, engenheiro.

Voltando aos filósofos clássicos: dizem Platão ou Aristóteles, em algum lugar, ser essa a exigência do jovem que vai ser filósofo? Ou podemos ver essa exigência em todos os outros filósofos clássicos? Na sua extensa e detalhada análise dos pensadores do passado, faz Aristóteles a menor menção a algo que lembre a noção de ‘criação de conceitos’ como critério para chamar alguém de 'filósofo’? O problema é que deveria estar neles essa exigência se é verdade que, essencialmente, a filosofia é criação de conceitos. Menciono Platão e Aristóteles como exemplo. Poderia usar Kant, Marx, Hegel, Schopenhauer, Nietzsche, Husserl, Heidegger, Wittgenstein. Se todos eles foram filósofos, como seria possível que a todos eles lhes passou inadvertida essa que seria a característica distintiva e definicional da filosofia? Por que, noutras palavras, essa característica aparentemente tão precípua, tão fundamental, tão definidora do que é fazer filosofia não é sequer mencionada por esses e outros filósofos consagrados?

Penso que, contrariamente à intenção e à letra da posição de Deleuze, que parece abertamente não autoritária nem tradicionalista, a forma como publicamente se apresenta essa definição é completamente oposta ao que um defensor da criatividade intelectual gostaria. Pois o que tem de destrutivo esse tipo de definições autoritárias de filosofia é que representam um obstáculo formidável para o desenvolvimento natural do pensamento filosófico, que não tem uma diferença de natureza respeito de determinadas formas de pensamento humano, mas de grau.

Como podemos saber antecipadamente que vamos criar um conceito filosófico sem ter um problema que, eventualmente, nos leve a pensar criativamente? E aqui menciono outra característica da reflexão filosófica. Ela pode ser igualmente filosófica sendo destrutiva ou negativa. Por exemplo, se é filosófico um argumento que quer provar determinada tese, é igualmente filosófica sua refutação, que é, em espírito, negativa, e que não pretende criar positivamente nada - certamente não um conceito -, a não ser que consideremos positiva a descoberta de um erro. Por outro lado, nem toda criação é positiva, assim como nem toda destruição, negativa. A criação de dogmas destrói a criatividade, enquanto que sua destruição liberta e abre o caminho para infinitas criações.

\footnotetext{
${ }^{\mathrm{i}}$ Texto apresentado no II Encontro Nacional do Grupo de Trabalho Filosofar e Ensinar a Filosofar da Associação Nacional de Pós-Graduação em Filosofia (ANPOF), ocorrido no Rio de Janeiro, nos dias 10 e 11 de setembro. A presente versão contém acréscimos e aprofundamentos.

ii Professor da Universidade Federal de Goiás (UFG). Correio eletrônico: gonzalo.armijos@gmail.com
} 